See Article page 733

\section{Commentary: Gender and opportunity in cardiothoracic surgery}

\section{Leora B. Balsam, MD}

Events of the past year have highlighted divisions among us. The choice to wear a mask during a global pandemic, an election seen as fairly won by some or stolen by others, and attitudes toward the Black Lives Matter movement are examples. Within our own specialty of cardiothoracic surgery, the drumbeat calling for inclusion and diversity has grown louder despite this global unrest. A burgeoning science has shown that a diverse workforce benefits both patients and providers, and at both individual and organizational levels, there is motivation to repudiate the culture of exclusion that has run deep in our field.

The present state is sobering, with women comprising only $7 \%$ of the cardiothoracic surgery workforce. A recent query of the Association of American Medical Colleges database found that $17 \%$ of cardiothoracic surgery faculty at academic institutions were women, compared with $27 \%$ in surgical specialties overall. ${ }^{1}$ The face of cardiothoracic surgeons remains predominantly male, despite the fact that more than one half of the population in the United States is female and more than one third of practicing physicians are female.

The subject is delicate, and individuals will view it through their own unique lens. While some may argue that entrance into our field should be merit-based, there are powerful influences that may open and close doors along the way without specific regard to merit. Moreover, the notion that merit itself can be objectively defined is overly simplistic.

In this issue of the Journal, Shemanski and colleagues ${ }^{2}$ find that the visibility of women in major cardiothoracic organizations is low. Between 2015 and 2019, they found that $11.1 \%$ of available executive board seats for the Society of

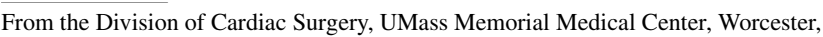
Mass.

Disclosures: The author reported no conflicts of interest.

The Journal policy requires editors and reviewers to disclose conflicts of interest and to decline handling or reviewing manuscripts for which they may have a conflict of interest. The editors and reviewers of this article have no conflicts of interest.

Received for publication Dec 8, 2020; revisions received Dec 8, 2020; accepted for publication Dec 8, 2020; available ahead of print Jan 8, 2021.

Address for reprints: Leora B. Balsam, MD, Division of Cardiac Surgery, UMass Memorial Medical Center, University Campus, 55 Lake Ave North, Worcester, MA 01655 (E-mail: leora.balsam@umassmemorial.org).

J Thorac Cardiovasc Surg 2021;161:745

$0022-5223 / \$ 36.00$

Copyright (c) 2020 by The American Association for Thoracic Surgery

https://doi.org/10.1016/j.jtcvs.2020.12.026
}

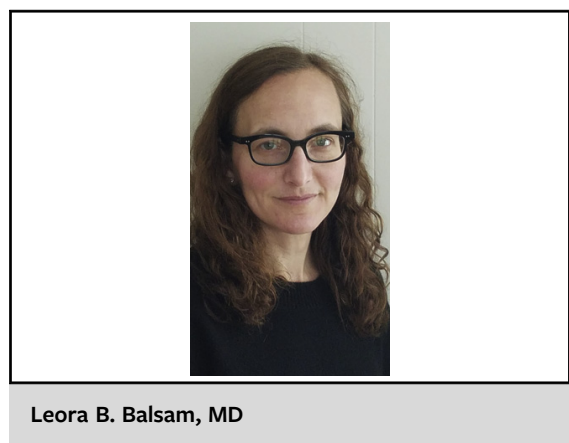

CENTRAL MESSAGE

Relative to the population, women are underrepresented in cardiothoracic surgery. Promoting a culture of diversity and inclusion will require individual and organizational change in our field.

Thoracic Surgeons (STS), American Association for Thoracic Surgery (AATS), Western Thoracic Surgical Association, and Southern Thoracic Surgical Association were occupied by women. At the annual meetings of these organizations, $13.1 \%$ of session leaders were female. The proportion of female session leaders was greatest in general thoracic surgery $(23.2 \%)$ and lowest in adult cardiac surgery $(6.9 \%)$. Over that same period of time, membership of women in the AATS and STS was approximately 7\%.

The study is a reminder of where we are now, and a call to arms for where we might go in the future. Why shouldn't women comprise a larger percentage of our workforce? In 2019, the Accreditation Council for Graduate Medical Education reported that $24 \%$ of cardiothoracic surgery trainees were women, ${ }^{1}$ so we should expect a shift toward greater female representation at all levels in our specialty. Our national and regional organizations should foster a culture of inclusion and lead the way for development of objective processes for recruitment, promotions, and merit-based compensation.

\section{References}

1. Ortmeyer KA, Raman V, Tiko-Okoye C, Espinosa J, Cooke DT, Erkmen C Women and minorities underrepresented in academic cardiothoracic surgery: it's time for next steps. Ann Thorac Surg. November 5, 2020 [Epub ahead of print].

2. Shemanski KA, Ding L, Kim AW, Blackmon B, Wightman S, Atay SM, et al Gender representation among leadership at national and regional cardiothoracic surgery organizational annual meetings. J Thorac Cardiovasc Surg. 2021;161: $733-44$. 